\title{
Expectant versus surgical management of incomplete abortions caused by self-intake of abortifacient drugs: results from a randomized controlled trial
}

\author{
Ankita Singh $^{1}$, Devendra Singh Kushwah ${ }^{2 *}$, Neha Khatik ${ }^{1}$, Beenu Kushwah ${ }^{1}$
}

\author{
${ }^{1}$ Department of Gynaecology, Shyam Shah Medical College, Rewa, Madhya Pradesh, India \\ ${ }^{2}$ Department of Pharmacology, Gajra Raja Medical College, Gwalior, Madhya Pradesh, India
}

Received: 01 April 2021

Revised: 25 April 2021

Accepted: 29 April 2021

\section{*Correspondence:}

Dr. Devendra Singh Kushwah,

Email: dev_singh433@yahoo.com

Copyright: (c) the author(s), publisher and licensee Medip Academy. This is an open-access article distributed under the terms of the Creative Commons Attribution Non-Commercial License, which permits unrestricted non-commercial use, distribution, and reproduction in any medium, provided the original work is properly cited.

\begin{abstract}
Background: Termination of unwanted pregnancies with medical method using recommended protocol based abortifacient drugs is a standard practice followed by obstetricians and gynaecologists worldwide which has a very successful outcome. However, self-administration of these drugs has become rampant because of certain social and practical issues resulting in complications and incomplete abortions as when these drugs are self-administered, recommended protocol is not generally followed. Traditionally incomplete abortions are managed by surgical curettage which itself is associated with procedure related complication and has been challenged by recent studies. Based on these studies many international guidelines have come out in support of expectant management of incomplete abortions. This study compared both of these management protocols to treat incomplete abortions caused by unprescribed intake of abortifacient drugs.

Methods: This was a one-year long prospective randomized controlled study in which total 782 females were randomized into two groups of 371 and 411. Group 1 was offered expectant management while group 2 was offered surgical curettage. Results were analysed using appropriate statistical tests.

Results: Group 1 showed a success rate of $86 \%$ while group 2 showed a success rate of $90 \%$ which was comparable. Overall complication rate was found to be higher in Surgical curettage group than in the group which underwent expectant management group.

Conclusions: Considering a very high number of patients coming with incomplete abortions caused by self-medication in present practice, expectant management seems to be a safer and more effective method and should be practice more widely.
\end{abstract}

Keywords: Abortifacient drugs, Incomplete abortions, Expectant management, Surgical curettage

\section{INTRODUCTION}

Abortions are legal in India since the enactment of MTP act 1971. MTP act provides clear guidelines and recommendation for termination of pregnancy which can be terminated only by registered medical practitioner after fulfilling certain conditions. ${ }^{1}$ According to MTP act 1971 which was amended in 2003, medical method of termination using tablet mifepristone \& misoprostol (abortifacient drugs), can only be administered by registered medical practitioners and gynaecologists upto 49 days from the first day of last menstrual period. ${ }^{2}$ Inspite of clear guidelines, self-administration of abortion pills at home by pregnant women themselves without any medical consultation has become rampant, fear of getting stigmatized and poor accessibility to safe abortion services 
in peripheral areas being the responsible factors. When these abortion pills are self- administered, proper drug regimen is usually not followed which has further worsened the situation and increased the burden of complications caused by incomplete abortions induced by this kind of self-medication. ${ }^{3,4}$ Literature from previous studies suggest that approximately $2 / 3 \mathrm{rd}$ of the total cases with incomplete abortion which seek hospital care are following self-administration of abortifacient has been responsible for high rate of surgical curettage. ${ }^{5,6}$ Surgical evacuation by dilatation and curettage (D\&C) of the product of conception has been the most commonly performed standard treatment since the 1930s, despite complications such as haemorrhage, infection, cervical tears, bowel and bladder damage, pelvic infection, broad ligament hematoma, uterine perforations, secondary infertility, asherman syndrome, as well as anaesthetic complications, apart from this it increase the cost and burden on healthcare. ${ }^{7,8}$ The incidence of serious morbidity following surgical evacuation has been estimated at $2.1 \%$ while the mortality is around $0.5 \%$ per $1,00,000 .^{9}$ Expectant management is alternative treatment in clinical practice and have shown to be effective and safe. ${ }^{10,11}$ It allowsthe continuation of the usual course of miscarriage, avoids complications from active management, and is more cost effective. A number of clinical studies describe that expectant management usually achieved complete evacuation within 2 weeks of diagnosis with low infection rate. $^{10-12}$

Recently, NICE guidelines and review by Cochrane also recommended that expectant management should be conducted in cases with uncomplicated abortions. ${ }^{12,13}$ At present we don't have much literature available from Indian researchers supporting this line of management in cases of incomplete abortions caused by unauthorized oneself medication.

The aim of the study was to conduct randomized controlled trial which aimed to assess the efficacy and acceptance of expectant management in comparison with surgical curettage for cases presented with incomplete abortion following self- administration of abortifacient drugs.

\section{METHODS}

It was a prospective randomized controlled study done over a period of one year from April 2019 to March 2020 at Shyam Shah Medical College and associated hospitals, Rewa, India. Ethical approval was obtained by Institutional Ethical Committee (human studies), Shyam Shah Medical College, Rewa. Women in early pregnancy who fulfilled the inclusion criteria and gave consents to be a part of study were randomly categorized in two groups by the use of random number computer tables. Group 1 was allocated expectant management and group 2 was allocated surgical management in the form of curettage.

All women were explained about the warning signs and were followed up after 15 days and at 1 and 2 months after first visit. Results were entered in a semi-structured format and were analysed subsequently.

\section{Inclusion criteria}

Inclusion criteria was patients as follows- (a) age $>18$ years, married; (b) history of taking pills for abortion for $>2$ weeks and < 3 weeks; (c) USG incomplete abortion with gestational age $8 \mathrm{gm} / \mathrm{dl}$ ); (d) no sign of infection; and (e) no systemic medical or surgical illness.

\section{Exclusion criteria}

Patients with (a) complete miscarriage; (b) intact gestational sac on USG; (c) twin or high order pregnancy; (d) molar pregnancy; (e) haemodynamically unstable (Hb38 degree C, raised TLC, tachycardia, malodourous vaginal discharge, lower abdominal tenderness); (f) heavy vaginal bleeding; and $(\mathrm{g})$ severe pain were excluded.

\section{Statistical analysis}

Appropriate statistical tests were applied as per the need. We tested differences for statistical significance using chi square test and data were analysed using the Statistical Package of the Social Sciences (SPSS, version 21.0).

\section{Study definitions}

Incomplete abortion- Incomplete abortion defined as evidence of intra-uterine remnants or an antero-posterior diameter of the uterine cavity exceeding $10 \mathrm{~mm}$ in ultrasound scanning. Successful outcome- A successful outcome was defined as the finding of an empty uterus (total endometrial diameter of $<10 \mathrm{~mm}$ ) on ultrasound scan, at 2 weeks follow-up, or an uneventful clinical course during 4 weeks of follow-up without complications or the need for (re)interventions.

Written consent was obtained from the patients after explaining them the nature and purpose of the study. They were assured that confidentiality would be strictly maintained. The option to withdraw from the study was always open.

\section{RESULTS}

Total number of participants were 962 who were eligible for study, but 101 participants refused to participate, so 861 were enrolled in study. Group 1- 430 were managed using expectant management. Group 2- 431 were managed using surgical evacuation. 59 participants lost to follow up from group 1, and 20 participants were lost to follow up from group 2 . Therefore, for data analysis 371 participants for expectant management and 411 participants for surgical evacuation were finally available.

Details of baseline characteristics, study outcomes and complication rates are mentioned in Table 1-3 respectively. 
Table 1: Baseline characteristics of study population.

\begin{tabular}{|lll|}
\hline $\begin{array}{l}\text { Baseline } \\
\text { characteristic }\end{array}$ & $\begin{array}{l}\text { Group 1 } \\
(\mathbf{N}=371) \\
(\%)\end{array}$ & $\begin{array}{l}\text { Group 2 } \\
(\mathbf{N}=411) \\
(\%)\end{array}$ \\
\hline $\begin{array}{l}\text { Age in years, Mean } \\
\text { (SD) }\end{array}$ & $27.6(3.44)$ & $29.1(7)$ \\
\hline Nulliparous & $86(23)$ & $117(28.5)$ \\
\hline Multiparous & $285(77)$ & $294(71.5)$ \\
\hline $\begin{array}{l}\text { Gestational age in } \\
\text { weeks, mean (SD) }\end{array}$ & $9.8(2.6)$ & $10(2.1)$ \\
\hline $\begin{array}{l}\text { Haemoglobin g/dl } \\
\text { (SD) }\end{array}$ & $9.7(0.67)$ & $9.3(0.69)$ \\
\hline
\end{tabular}

Table 2: Outcome of study groups.

\begin{tabular}{|lll|} 
Outcome & $\begin{array}{l}\text { Group 1 } \\
(\mathbf{N = 3 7 1 )} \\
(\%)\end{array}$ & $\begin{array}{l}\text { Group 2 } \\
(\mathbf{N}=411) \\
(\%)\end{array}$ \\
\hline Successful & $319(86)$ & $373(90)$ \\
\hline Unsuccessful & $52(14.02)$ & $40(9.7)$ \\
\hline Acceptable & $257(69)$ & $214(52)$ \\
\hline
\end{tabular}

Table 3: Complication rates of study groups.

\begin{tabular}{|lll|}
\hline Complication rates & $\begin{array}{l}\text { Group 1 } \\
(\mathbf{N = 3 7 1 )} \\
(\%)\end{array}$ & $\begin{array}{l}\text { Group 2 } \\
(\mathbf{N}=411) \\
(\%)\end{array}$ \\
\hline $\begin{array}{l}\text { Use of additional } \\
\text { analgesia }\end{array}$ & $286(77)$ & $322(78)$ \\
\hline $\begin{array}{l}\text { Blood transfusion } \\
\text { Pelvic inflammatory } \\
\text { disease }\end{array}$ & $10(2.7)$ & $7(1.7)$ \\
\hline Cervical tear & $26(7)$ & $63(15)$ \\
\hline Uterine perforation & 0 & $18(4.4)$ \\
\hline $\begin{array}{l}\text { Unplanned } \\
\text { admission }\end{array}$ & $22(6)$ & $15(1.9)$ \\
\hline $\begin{array}{l}\text { Asherman } \\
\text { syndrome }\end{array}$ & 0 & $9(2.1)$ \\
\hline
\end{tabular}

\section{DISCUSSION}

Since the legalization of MTP act, the rates of abortions have increased. The MTP Act 1971 (2003 Amendment) clearly define guidelines for medical termination of pregnancy which must be conducted by registered medical practitioners and gynaecologistsup to 49 days from the first day of last menstrual period. ${ }^{3}$ With strict adherence to these guidelines, failure rates i.e. incomplete abortion rate is very low. In spite of legalization and confidentiality, self-administration of abortifacient drugs to terminate the pregnancy is common. The factors responsible for opting abortion outside the accredited institution include absence of health care facility in rural areas, high cost in private hospitals, lack of awareness to the beneficiaries, poor perceived quality of care in government facilities as well as lack of confidentiality. ${ }^{14}$ However, failure rate as well as complication rate following self-administration is high. ${ }^{7}$ When such patients seek medical care, deciding appropriate line of management is necessary. Surgical evacuation is commonly followed, however, recent international guidelines recommend expectant management for such patients whenever possible. The present study was thus conducted at tertiary care centre to evaluate efficacy of expectant management in induced incomplete abortions resulting from self-administration of abortifacient drugs and to compare its efficacy with that of surgical management.

In present study success rate of expectant management and surgical management was found to be comparable, which was $82 \%$ and $95 \%$ respectively which is comparable to other stuudies. ${ }^{15-19}$ Infection rate was found to be higher in surgical group as shown in other studies as well. ${ }^{15,20}$ The rate of emergency blood transfusion was found to be higher in expectant group (2.7\%) than surgical group $(1.7 \%)$ which is in accordance with previous studies. Rate of procedure related complication like cervical perforation, uterine perforation and asherman syndrome was nil in expectant group while it was found to be in the range of $2-4 \%$ in surgical group. Need for additional analgesia was found to be high in surgical group for obvious reasons. These all are comparable with previous studies. ${ }^{15,16,20}$ Acceptability of the allocated method was found to be significantly higher in expectant group than surgical group, most common reason being less pain and apprehension of undergoing a surgical intervention which has been supported by our own study done on this topic a year back with lesser number of study participants. ${ }^{6}$

Present study is one of its kind on a very relevant topic, however being a single institute study, generalization of results may not be prudent at this point of time, specially to rural population where loss to follow up while observing in expectant management can be a big obstacle.

\section{CONCLUSION}

Based on the findings of present study, it could be concluded that success rate of expectant management for incomplete abortion as effective as surgical evacuation but patients morbidity as determined by the requirement of antibiotic, duration of pain, bleeding and sick leave were significantly lower in expectant management group. Overall, complication rates were much lower in expectant management group when compared to surgical management group.

Incidence of incomplete abortion and unplanned admission were higher in expectant group whereas procedure related complications were higher in surgical evacuation group. To conclude, expectant management is an acceptable method with high success rate.

Funding: No funding sources

Conflict of interest: None declared

Ethical approval: The study was approved by the Institutional Ethics Committee 


\section{REFERENCES}

1. Technical Operations division, Ministry of Health and Family welfare. Manual for first trimester medical termination of pregnancy, 1971. Available at: http://tcw.nic.in/Acts/MTP-Act-1971. Accessed on 18 February 2021.

2. Government of India. The medical termination of pregnancy rules (amendment), 2003. Available at: Available at: http://tcw.nic.in/Acts/MTP-Act-1971. Accessed on 18 February 2021. Accessed on 18 February 2021.

3. Hirve SS. Abortion law, policy and services in India: a critical review. Reprod Health Matters. 2004;12(24):114-21.

4. Thaker RV, Deliwala KJ, Shah PT. Self-medication of abortion pill: women's Health in jeopardy. NHL J Med Sci. 2014;3(1):26-31.

5. Mundle S, Elul B, Anand A, Kalyanwala S, Ughade S. Increasing access to safe abortion services in rural India: experiences with medical abortion in a primary health center. Contraception. 2007;76(1):66-70.

6. Kushwah B, Kushwah DS. A randomized controlled study on expectant management of incomplete abortions cause by self medication. Int $\mathrm{J}$ Basic Clin Pharmacol. 2019;8:1409-12.

7. You JH, Chung TK. Expectant, medical or surgical treatment for spontaneous abortion in first trimester of pregnancy: a cost analysis. Hum Reprod. 2005;20(10):2873-8.

8. Hooker AB, Lemmers M, Thurkow AL, Heymans MW, Opmeer BC, Brolmann HA, et al. Systematic review and meta-analysis of intrauterine adhesions after miscarriage: prevalence, risk factors and longterm reproductive outcome. Hum Reprod Update. 2014;20(2):262-78.

9. Lawson HW, Frye A, Atrash HK, Smith JC, Shulman HB, Ramick M. Abortion mortality, United States, 1972 through 1987. Am J Obstet Gynecol. 1994;171(5):1365-72.

10. Royal College of Obstetricians and Gynaecologists. Management of early pregnancy loss, 2006. Available at: https://www.rcog.org.uk/en/guidelines-research. Accessed on 18 February 2021. Accessed on 18 February 2021.

11. Jurkovic D, Ross JA, Nicolaides KH. Expectant management of missed miscarriage. $\mathrm{Br} \mathrm{J}$ Obstet Gynaecol. 1998;105(6):670-1.

12. Casikar I, Bignardi T, Riemke J, Alhamdan D, Condous G. Expectant management of spontaneous first-trimester miscarriage: prospective validation of the '2-week rule'. Ultrasound Obstet Gynecol. 2010;35(2):223-7.

13. Nanda K, Peloggia A, Grimes D, Lopez L, Nanda G. Expectant care versus surgical treatment for miscarriage. Cochrane Database Syst Rev. 2006;(2):3518.

14. Government of India. Health and family welfare, Statistics division, Rural health statistics, 2019. Available at: https://main.mohfw.gov.in/sites/default/files/Healtha ndFamilyWelfarestatisticsinIndia. Accessed on 18 February 2021.

15. Wieringa DWM, Hartman EE, Ankum WM, Reitsma JB, Bindels PJ, Bonsel GJ. Expectant management versus surgical evacuation in first trimester miscarriage: health-related quality of life in randomized and non-randomized patients. Hum Reprod. 2002;17(6):1638-42.

16. Trinder J, Brocklehurst P, Porter R, Read M, Vyas S, Smith L. Management of miscarriage: expectant, medical, or surgical? Results of randomised controlled trial (miscarriage treatment (MIST) trial). BMJ. 2006;332(7552):1235-40.

17. Wijesinghe PS, Padumadasa GS, Palihawadana TS, Marleen FS. A trial of expectant management in incomplete miscarriage. Ceylon Med J. 2011;56(1):10-3.

18. Maani W, Solomayer EF, Hammadeh M. Expectant versus surgical management of first-trimester miscarriage: a randomised controlled study. Arch Gynecol Obstet. 2014;289(5):1011-5.

19. Lemmers M, Verschoor MAC, Oude RK, Naaktgeboren C, Bossuyt PM, Huirne JAF, et al. MisoREST: Surgical versus expectant management in women with an incomplete evacuation of the uterus after misoprostol treatment for miscarriage: A cohort study. Eur J Obstet Gynecol Reprod Biol. 2017;211:83-9.

20. Bagratee JS, Khullar V, Regan L, Moodley J, Kagoro H. A randomized controlled trial comparing medical and expectant management of first trimester miscarriage. Hum Reprod. 2004;19(2):266-71.

Cite this article as: Singh A, Kushwah DS, Khatik N, Kushwah B. Expectant versus surgical management of incomplete abortions caused by selfintake of abortifacient drugs: results from a randomized controlled trial. Int J Basic Clin Pharmacol 2021;10:660-3. 